\title{
Factors Influencing Online Game-Based Learning Effectiveness
}

\author{
Segomotso Mosiane and Irwin Brown \\ Department of Information Systems, University of Cape Town, South Africa \\ irwin.brown@uct.ac.za \\ DOI: 10.34190/EJISE.20.23.1.006
}

\begin{abstract}
There is a general consensus that games are effective as learning tools. There is however, a lack of knowledge regarding what makes online games effective as learning tools. The purpose of this study is therefore to answer the question: What are the factors influencing online game-based learning effectiveness? The aim of this paper is to develop a conceptual framework that reflects the factors influencing online game-based learning effectiveness. The conceptual framework combines concepts from the Information Systems Success Model, Task-Technology Fit Model and Flow theory. The study used a quantitative method. Data was collected using an online instrument. The study used 134 respondents from mainly the United Kingdom, United States and South Africa. The model was validated using confirmatory factor analysis and tested using Smart-PLS to assess path coefficients. The identified factors influencing Knowledge Improvement, the key measure chosen for learning effectiveness with online game-based learning, are Game-Task Fit, Flow (where Flow consists of dimensions of Goal Orientation/Feedback and Concentration) and Perceived Usefulness. The utilitarian factors of Game-Task Fit and Perceived Usefulness have a stronger effect on Knowledge Improvement than Flow. On the other hand Flow was the only one of these three variables to have an influence on intensity and frequency of game use, suggesting a hedonic motivation for intense and frequent game usage. These increases in game usage do not necessarily translate into Knowledge Improvement suggesting that the link between game use and Knowledge Improvement may not be a simple linear relationship. Game Quality influences Game-Task Fit, while Information Quality influences both Flow and Game-Task Fit.
\end{abstract}

Keywords: Game-Based Learning, Effectiveness, IS Success, Task-Technology Fit, Flow

\section{Introduction}

E-learning environments use multimedia tools that can include still images, animation, video, and audio presentations (Moos and Marroquin, 2010). Online game-based learning environments use a combination of these techniques (Hess and Gunter, 2013). Online game-based learning environments are found to have positive attributes not present with traditional instruction (Chiu, Kao and Reynolds, 2012; Girard, Ecalle and Magnan, 2013; Jung and Won-Hyung, 2013). Educational games combine curriculum goals with gameplay in order for individuals to reach a learning outcome (Nicholson, 2011). Educational games are also referred to as serious games, which have the purpose of teaching a specific skill (Annetta, 2010, Connolly, et al., 2012). The concept of learning with games is particularly interesting to individuals who incorporate technology into their daily lives, i.e. the Net generation (Bekebrede, Warmelink and Mayer, 2011; Girard, Ecalle and Magnan , 2013; Gu, Zhu and Guo, 2013). Individuals who fall under the Net generation are also of interest because the manner in which they think and learn differs from that of other generations (Morris, 2011; So, et al., 2012).

The Net generation comprises individuals born after 1982 (Valtonen, et al., 2011). This classification emerges from the idea that individuals born in this period have lifestyles that depend on technology and are fascinated with new technologies (Evans and Forbes, 2012). In contrast to previous generations, these individuals use digital media more than any previous generation (Rosen, 2011). Digital immigrants are people who were not born in a world driven by technology, but join the technology world to an extent that they become digitally fluent (Valtonen, et al., 2010).

Games have proven to be as effective, or more so in some instances, than traditional classroom methods (Chin, Dukes and Gamson, 2009), hence there is growing interest in assessing the effectiveness of educational games (Girard, Ecalle and Magnan , 2013; Hess and Gunter, 2013; All et al., 2017). Measuring the effectiveness of online game-based learning is problematic because there is a diversity of perspectives on what makes games effective for learning (Vogel, et al., 2006; Guillén-Nieto and Aleson-Carbonell, 2012). Three major theoretical perspectives are apparent in the broader e-learning effectiveness literature - studies that draw from Information Systems (IS) theories such as the DeLone and McLean $(1992,2003)$ IS success model, and its adaptations (Seddon, 1997); studies that rely on task-technology fit theory (Goodhue and Thompson, 1995), and finally those that make reference to flow theory (Hoffman and Novak, 2009). Better insight and richer theorising can be achieved

CACPIL

Reference this paper: Mosiane, S., and Brown, I., 2020. Factors Influencing Online Game-Based Learning Effectiveness. The Electronic Journal of Information Systems Evaluation, 23(1), pp. 79-95, available online at www.ejise.com 
through integration of perspectives (Grover and Lyytinen, 2015). Hence the purpose of this study is to pose the question: What factors influence online game-based learning effectiveness? The paper will begin with the theoretical background and framework development, after which the research methodology will be discussed. The results and a discussion of the results will follow before the paper is concluded.

\section{Theoretical Background}

The three theoretical bases of the study will be discussed in turn, i.e. the DeLone and McLean IS success model, the task-technology fit theory and flow theory respectively.

The IS Success Model and its adaptations are widely used as a basis for research on IS effectiveness (DeLone and McLean, 1992; DeLone and McLean, 2003). IS effectiveness in this line of research is taken as synonymous with IS success, which in turn is seen to be a multi-dimensional construct. The original model posits System Quality, Information Quality, Use, Satisfaction and Individual and Organisational Impact as dimensions of IS success (DeLone and McLean, 1992). Subsequent studies suggest the inclusion of Perceived Usefulness as a dimension of success (Seddon, 1997), and the consideration of Net Benefits rather than Individual and Organisational Impact as the ultimate dependent variable, or measure of effectiveness (DeLone and McLean, 2003; Seddon, 1997). Further adaptations have been used to investigate success in specific online contexts, such as with regards to e-commerce success, e-government success, e-learning success (Khayun, Ractham and Firpo, 2012; Wang, Wang and Shee, 2007) as well as evaluation of user experience with serious games (Cohard, 2019). There is hence a strong justification for using this model as a basis for investigating success of online game-based learning given its versatility.

In order to ensure that pedagogical foundations of a game are met, the goal of the educational game needs to match the learning task (Del Blanco et al., 2012; Lee, Cerreto and Lee, 2010; Wu, et al., 2012). The fit between a learning task and the game is important because tension between the goal of the game and the learning outcome decreases its learning effectiveness (Brom, Šisler and Slavík, 2010). In e-learning environments, the fit between the task and technology has been shown to lead to effectiveness, synonymous in this context with improved learning performance (Lin, 2012). Fit is defined as "the degree to which a technology assists an individual in performing his or her portfolio of tasks" (Robles-Flores and Roussinov, 2012, p.441). In this context, fit refers to the degree that a game assists an individual in performing his or her learning task. The TaskTechnology Fit theory suggests that fit leads to improved performance (Goodhue and Thompson, 1995). The use of the Task-Technology Fit model is evident in a number of e-learning studies. Examples are studies on learning management systems (McGill, Klobas and Renzi, 2011), question-answering technology (Robles-Flores and Roussinov, 2012) blended e-learning systems (Ma, Chao and Cheng, 2013), serious games (Khojah, 2019), and gamification (Vanduhe et al, 2020). Task Technology Fit will become Game-Task Fit in this study.

Educational games have a utilitarian and a hedonic purpose. While measures such as Perceived Usefulness in the modified IS success model and task-technology fit account for assessment of utilitarian purposes, studies have turned to flow theory to investigate enjoyment (Fu, Su and $\mathrm{Yu}, 2009)$. Flow refers to the "the complete engagement with and immersion in an activity" (Hoffman and Novak, 2009). The application of the flow theory extends to a number of fields including educational research (Hsu and Lu, 2004). Operationalising and measuring Flow has proven challenging, with Flow being treated as either a uni-dimensional construct or multi-dimensional construct (Hoffman and Novak, 2009). Studies of Flow in the context of online games have been quite prevalent (Pertulla et al., 2017). For example, Hsu and Lu (2004) used a unidimensional measure for flow experience, and integrated it into the technology acceptance model. Chang et al. (2018) used a three-dimensional measure comprised of enjoyment, engagement and control. Fang, Zhang and Chan (2013) developed and validated a multi-dimensional model of flow for computer games, comprising of the following dimensions - Clear Goals, Feedback, Concentration, Immersion, Control, Autotelic experience and Challenge. Each will be discussed in turn.

Clear Goals - Games are goal-oriented experiences (Bellotti, et al., 2013) and game-based learning is a goaldirected process (Hong, et al., 2009). Clear Goals in games are a necessary feature to facilitate high-quality education (Jovanovic et al., 2011). Games that lack clear objectives may result in individuals misinterpreting the actual goal of the game and therefore it could lead to negative learning outcomes (Charoenying, 2010). Goalorientation in games is aligned with the Net generation who are goal-orientated (Walter, 2013). 
Feedback - Feedback is a "critical component of any learning process because it allows learners to reduce the discrepancy between actual and desired knowledge" (Butler, Godbole and Marsh, 2013, p.290). The feedback that a player gets during a game allows them to track their progress towards achieving the goal of the game (Cornillie, Clarebout and Desmet, 2012; Erhel and Jamet, 2013). Instant feedback that games provide allow the learner to receive suggestions that assists them in correcting areas of weakness immediately (Jong, et al., 2013). Instant feedback is an advantage for the Net generation who prefer instant gratification (Walter, 2013) and demand real-time fast processing (Skiba and Barton, 2006).

Concentration on a particular topic influences the learning process of a student (Khanlarian and Singh, 2014). Concentration decreases if there are distracting stimuli outside of the focus area (Pace, 2004). This is because human memory can provide full attention to one item rather than more than one (Janczyk and Grabowski, 2011). Games increase the attention that the player commits to a task (Hess and Gunter, 2013).

Immersion is the "extent to which the individual is absorbed in the activity" (Whitton, 2011, p.605). Immersion in a task increases the motivation to learn (Annetta, 2010). Additionally, the more immersion that takes place during a game, the greater the level of engagement takes place (Li, et al., 2014). Games cause players to be emotionally committed and involve themselves cognitively (Besharat, et al., 2013). Games also allow players to experience an alternative reality (Calleja, 2007). The immersion of players in an alternate reality leads to learning (De Freitas and Oliver, 2006; Dalgarno and Lee, 2010) and increases the enjoyment of the player (Poels, de Kort and IJsselsteijn, 2012). Immersion is an advantage for the Net generation because this generation is said to be inclined towards a shorter attention span (Walter, 2013).

Control - It is important that users feel "in control of [their] actions and of the environment" (Fang, Zhang and Chan, 2013, p.457). Interactivity helps a user to be in control, as it describes "different ways in which the learner can navigate access and manipulate learning material within a specific learning environment" (Domagk, Schwartz and Plass, 2010, p.1025). The interactivity in a game is directly proportional to the extent that a player can manipulate and alter the content of the game (Shafer, Carbonara and Popova, 2011). This interactivity allows the player to have control over the pace and content of the game (Domagk, Schwartz and Plass, 2010). Control is also important because enjoyment from a game stems from being in control, struggling to gain control or even the suspense of the potential of losing control (Poels, de Kort and IJsselsteijn, 2012).

Autotelic experience is "the key element of an optimal experience that is an end in itself. The activity consumes and becomes intrinsically rewarding" (Fang, Zhang and Chan, 2013, p.457). Intrinsic motivation is an "internal desire to engage in behaviour due to pleasure, interest, enjoyment, and/or challenge" (Moos and Marroquin, 2010, p.267). Motivation increases the interest that individuals have in completing tasks (Cerasoli and Ford, 2014). The fun in games triggers motivation to pay attention and engage in the educational material, hence increasing the autotelic experience (Peng, 2009). The motivation to complete tasks is particularly important to the Net generation who get bored easily (Walter, 2013).

Challenge is a necessary factor in learning environments, because tasks that provide challenge result in higher levels of learning (Hughes, 2010). The challenging characteristics of games cause the internalisation of knowledge (Chang, Peng and Chao, 2010). Challenge also triggers the curiosity in a player and therefore leads to more exploration in the game, which leads to learning (Feng, 2011). Challenge is an important factor for the Net generation who are curious and prefer exploration (Skiba and Barton, 2006).

\section{Conceptual framework development}

By drawing from concepts derived from the IS success model, task-technology fit theory and flow theory, a model of online game-based learning effectiveness is developed. The key concepts derived from these theoretical bases, and relationships between the concepts will be discussed next.

\subsection{Net Benefit of online game-based learning - Knowledge improvement}

Net Benefits of use represent the ultimate dependent variable in the DeLone and McLean (2003) updated IS success model. Hence in this study it will be taken to be the ultimate measure of effectiveness. DeLone and McLean (2003) raise three questions that require an answer before using Net Benefits as a measure of effectiveness. These are: What qualifies as a benefit? For whom? At what level of analysis? To answer the first question, the impact of online game-based learning ought to be knowledge improvement or learning. To answer 
the second question, the focus should be on the game user, or learner (Hamam and Saddik, 2013). To answer the third question, the level of analysis should be at an individual level (Khanlarian and Singh, 2014). Knowledge Improvement is a key dimension of effectiveness in an online game-based learning context (Fu, Su and Yu, 2009; Lin et al., 2017).

\subsection{Use of online game-based learning}

Use of a system has long been recognised as an indicator of IS success or effectiveness, particularly where such usage is voluntary (DeLone and McLean, 2003), and where there are other options to perform the same task. Specifically, post-adoption usage of a technology is deemed necessary for success (Thong, Hong and Tam, 2006). Playing an online game is a system-use behaviour, often performed voluntarily (Kuss, Louws and Wiers, 2012). Hence its usage can be considered as an important variable in assessing the effectiveness of online game-based learning. Use of a technology has an influence on net benefits gained from use (DeLone and McLean, 2003; Seddon, 1997). This has been confirmed in the context of e-learning (Chen, 2010). In the case of online gamebased learning increased usage should lead to the ultimate benefit of Knowledge Improvement, which leads to the following hypotheses:

H1: The greater the Use of online game-based learning, the greater the Knowledge Improvement.

\subsection{Perceived Usefulness}

The inclusion of Perceived Usefulness in the DeLone and McLean IS success model gives due recognition to this perception as an important variable in assessing the effectiveness of an IS (Seddon, 1997). Perceived Usefulness is not only a pre-adoption belief that signals an intention to use a technology, but a post-adoption belief as well, which influences continued usage (Saeed and Abdinnour-Helm, 2008; Vanduhe et al, 2020). The influence of Perceived Usefulness on Usage has been confirmed in an e-learning context (Chen, 2010). This leads to the following hypotheses:

H2: The greater the Perceived Usefulness of online game-based learning, the greater the game Use.

In online game-based learning, Perceived Usefulness accounts for the utilitarian purpose of educational games. which leads to Knowledge Improvement or learning (Brom, Preuss and Klement, 2011; Jovanovic, et al., 2011; Chen, et al., 2012). It follows then that the more useful online game-based learning is perceived, the greater the Knowledge Improvement. This leads to the following hypotheses:

H3: The greater the Perceived Usefulness of online game-based learning the greater the Knowledge Improvement.

\subsection{Game-Task Fit}

Task-Technology Fit theory posits that fit contributes to both greater use of a technology and improved individual performance (Goodhue and Thompson, 1995). Lin (2012) confirms these relationships hold strong in the context of e-learning, where the fit between a learning task and a virtual learning system was shown to have strong influence on usage of the learning system, and its impact on learning. Similarly, Khojah (2019) demonstrate the impact of task-technology fit on perceived learning with serious games. In the context of online game-based learning, instead of task-technology fit, it is useful to refer to the Game-Task Fit. The following hypotheses can be inferred concerning Game-Task Fit:

H4: The greater the Game-Task Fit in online game-based learning the greater the game Use

H5: The greater the Game-Task Fit in online game-based learning the greater the Knowledge Improvement.

Task-technology fit has been shown to be associated with Perceived Usefulness when considering the use of YouTube for procedural learning (Lee and Lehto, 2013). This lends support to the following hypothesis:

H6: The greater the Game-Task Fit in online game-based learning the greater the Perceived Usefulness. 


\subsection{Flow}

The concept of Flow has been researched widely in e-learning and computer games literature, given its importance to successful game-play (Kiili, 2005; Pertulla, 2017). Pertinent to e-learning, studies have revealed that Flow contributes to positive learning outcomes. In the specific context of online game-based learning this relationship has been affirmed (Kiili, 2005; Cheng, She and Annetta, 2015), which lends support to the following hypothesis:

H7: The greater the level of Flow in online game-based learning the greater the Knowledge Improvement.

An increased flow experience leads ultimately to greater exploratory behaviour (Kiili, 2005) and hence usage of a system (Hoffman and Novak, 2009). There is support then for the following hypothesis:

H8: The greater the level of Flow in online game-based learning the greater the game Use.

Finally, Flow has been found to lead to greater perceptions of the usefulness of a system (Hoffman and Novak, 2009), hence leading to the following hypothesis:

H9: The greater the level of Flow in online game-based learning the greater the Perceived Usefulness.

\subsection{Game Quality}

System quality takes cognisance of issues such as ease of use, usability, availability, reliability, adaptability and response time of a system (Delone and McLean, 2003). In the context of game-based learning, Game Quality is the equivalent concept of interest. The characteristics of the game should promote Game Quality (Hamam and Saddik, 2013). A well-designed game is more likely to contribute towards learning effectiveness (Mwangi, Waweru, and Mwathi, 2011). In studies of IS success, system quality is shown as an influence on Perceived Usefulness (Seddon, 1997), a relationship confirmed with e-learning systems (Chen, 2010). It follows that Game Quality will have an influence on Perceived Usefulness. This leads to the following hypotheses:

H10: The greater the Game Quality in online game-based learning the greater the Perceived Usefulness.

Task-technology fit theory acknowledges that the characteristics of the technology are an important antecedent to fit (Goodhue and Thompson, 1995). In IS research system quality and information quality are the essential characteristics that represent the system (Delone and McLean, 2003). The better the system quality, or game quality in online game-based learning, the better the fit for purpose. The leads to the following hypothesis:

H11: The greater the Game Quality in online game-based learning the greater the Game-Task Fit.

System attributes known to influence Flow include ease of use, usability, response time, and navigational cues (Hoffman and Novak, 2009). All these are captured by the system quality concept in IS success, which we refer to as Game Quality in online game-based learning environments. There is hence support for the following hypothesis:

H12: The greater the Game Quality in online game-based learning the greater the Flow.

\subsection{Information Quality}

Information Quality refers to the precision, relevance, sufficiency, timeliness and currency of information (DeLone and McLean, 2003). For effective performance it is important that the information from a system is necessary, correct, current, up-to-date and appropriate (Setia, Venkatesh and Joglekar, 2013). It is wellestablished in IS success literature that Information Quality enhances perceptions of usefulness of a system (Seddon, 1997). This has been confirmed in the context of e-learning (Chen, 2010), hence the following hypotheses is suggested:

H13: The greater the Information Quality of online game-based learning the greater the Perceived Usefulness. 
Information Quality is a key technological characteristic of an IS (Delone and McLean, 2003), and hence it would have a bearing on the task-technology fit (Goodhue and Thompson, 1995). In like manner, the Information Quality of a game would have a bearing on the game-task fit. This leads to the following hypothesis:

H14: The greater the Information Quality of online game-based learning the greater the Game-Task Fit.

Content characteristics and content interest have been noted as antecedents of Flow (Hoffman and Novak, 2009). These themes are akin to the concept of Information Quality, hence the hypothesis:

H15: The greater the Information Quality of online game-based learning the greater the Flow.

\subsection{Research Model}

Figure 1 provides a graphical representation of the conceptual framework that encapsulates the set of concepts and hypotheses discussed previously.

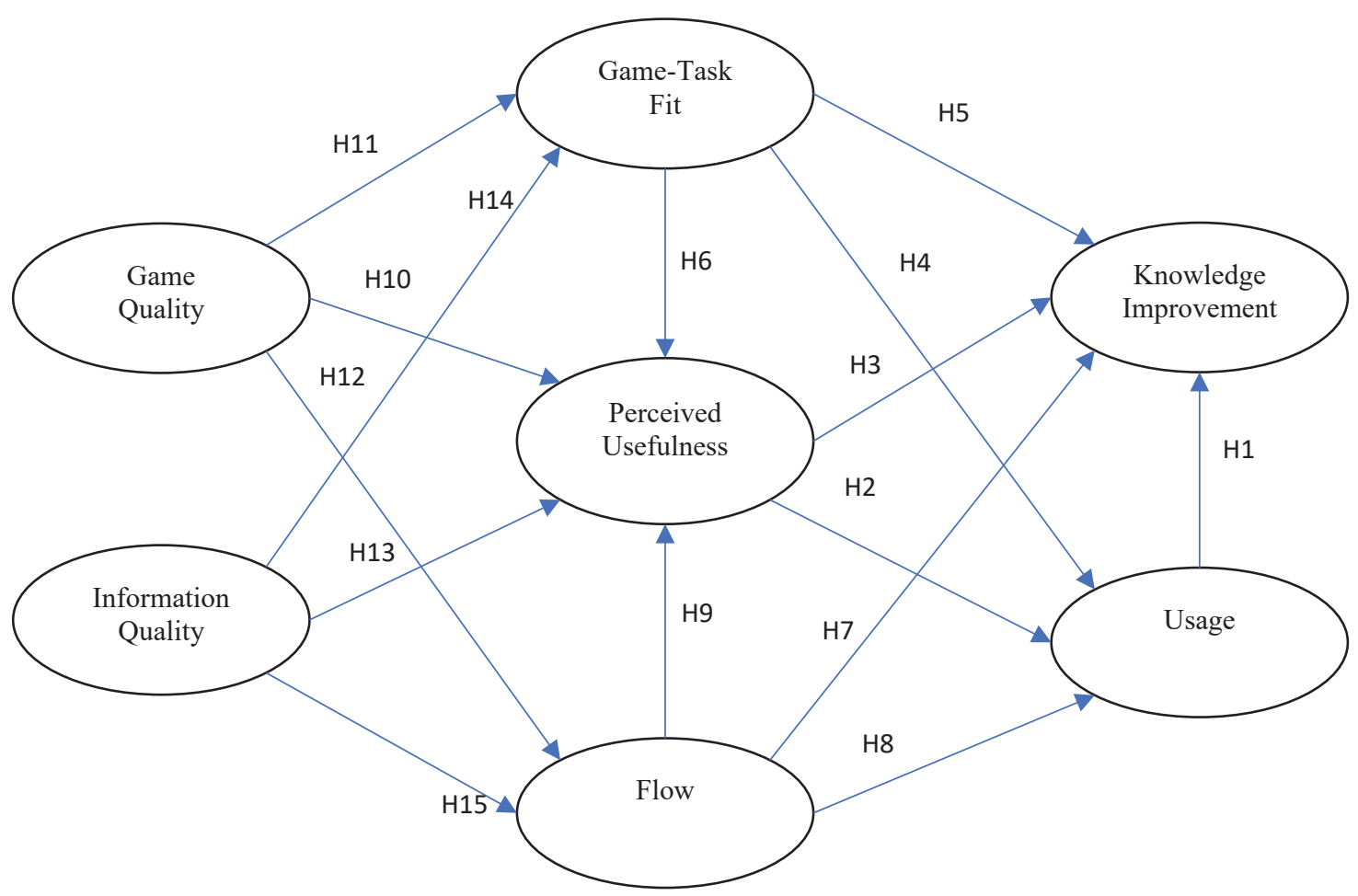

Figure 1: Proposed Conceptual Model

\section{Research Methodology}

The study employed a quantitative survey approach to gather data and test hypotheses. In this section, the instrument development will be explained, followed by a discussion of the data collection procedure, then instrument refinement achieved through tests of validity and reliability.

\subsection{Instrument development}

For all the constructs in the conceptual model, validated measures exist. These measures were hence identified, and where necessary modified to fit the context of online game-based learning. Fang, Zhang and Chan (2013) developed an instrument for measuring Flow in computer game-play, where Flow was conceptualised as having seven dimensions as in Table 1. Perceived Usefulness was measured based on an instrument developed by Lee and Lehto (2013) in a study of YouTube use for procedural learning. The measure for Game-Task Fit was taken from Lin (2012) who investigated web learning performance. Game Quality and Information Quality were measured based on an instrument designed to measure e-learning success (Wang, Wang and Shee, 2007), whilst the Knowledge Improvement measure was drawn from Fu, Su and $\mathrm{Yu}$, (2009) who designed an instrument to measure enjoyment of e-learning games. The Use measure was taken from Teo, Lim and Lai (1999) in a study on Internet use. The final refined instrument is shown in Appendix 1. All items, with the exception of items to 
measure Use, used a 5-point Likert scale anchored by "Strongly Agree" at one end and "Strongly Disagree" at the other. The measures for Use were length of use $(7$ scales varying from less than 1 month to more than 5 months), frequency of use ( 7 scales varying from Rarely to a few times a day), intensity of use ( 7 scales varying from Rarely to more than 4 hours a time), and extent of use [Interval scale from 1 to 7 ].

Table 1: Measures, number of items and measurement sources

\begin{tabular}{|l|c|l|}
\hline \multicolumn{1}{|c|}{ Measures } & Number of Items & \multicolumn{1}{c|}{ Source } \\
\hline Goal Orientation & 3 & Fang, Zhang and Chan (2013) \\
\hline Feedback & 3 & Fang, Zhang and Chan (2013) \\
\hline Autotelic experience & 2 & Fang, Zhang and Chan (2013) \\
\hline Challenge & 4 & Fang, Zhang and Chan (2013) \\
\hline Control & 2 & Fang, Zhang and Chan (2013) \\
\hline Immersion & 2 & Fang, Zhang and Chan (2013) \\
\hline Concentration & 2 & Fang, Zhang and Chan (2013) \\
\hline Perceived Usefulness & 4 & Lee and Lehto (2013) \\
\hline Game Quality & 7 & Wang, Wang and Shee (2007) \\
\hline Information Quality & 6 & Wang, Wang and Shee (2007) \\
\hline Game-Task Fit & 6 & Lin (2012) \\
\hline Use & 4 & Teo, Lim and Lai (1999) \\
\hline Knowledge improvement & 5 & Fu, Su and Yu (2009) \\
\hline
\end{tabular}

The instrument also included demographic data of the participants. These items were age, gender, level of education, geographical location, gaming skill level and information on how recently the participant had played the game.

\subsection{Data collection}

The research target population consisted of individuals who are a part of the Net generation who participate in online game-based learning. The distribution of the instrument was online. A pilot study was conducted amongst a group of university students who made no major suggestions for improvement to the questionnaire. The questionnaire was hosted online by Qualtrics Panels, LLC. Qualtrics was commissioned to source and invite participants to fill out the instrument after completing a pre-screening. The conditions to participate in this study were that the age of the participant must fall within the Net generation and that the participant must have recently played a game for learning voluntarily. They were required to answer the questionnaire based on the game they had most recently played. The use of Qualtrics and other providers for such panel surveys is increasingly prevalent in academic research, and is deemed a valid approach to sourcing data from required target populations (Cardella, Ewing and Williams, 2016, Lowry, et al., 2016; Pennington and Kelton, 2016). A sample size was determined, based on the assumption that there should be at least 10 participants per independent variable being assessed (Barlett, Kotrlik and Higgins, 2001). In this paper, there were 6 independent variables, but Flow was a multi-dimensional construct with 7 dimensions, hence making a total of 12 independent variables (120 required respondents). A sample of 150 respondents was deemed more than sufficient.

The data collection process took approximately one week in 2016. The total number of responses received was 152. 27 of these responses were excluded from the data. There were three criteria used to decide which responses were invalid. The first was if the response did not specify a valid game purpose or learning outcome. The second was if the game purpose or the learning outcome was unclear. The final criterion was if the game did not support the given game purpose or learning outcome. The final number of valid responses used was 134. The next section discusses the measurement refinement process.

\subsection{Instrument validity, reliability and refinement}

As aforementioned, the use of previously defined measurement items was to ensure validity and reliability of the instrument. This section verifies if the instrument was indeed valid and reliable, and specifies how the measures were refined to improve validity and reliability. 


\subsubsection{Construct validity}

Confirmatory factor analysis was used to test construct validity. The extraction method was principle component analysis, using a minimum eigenvalue of 1 as a cut-off value for extraction. The factor rotation method was varimax-normalised rotation. Items were excluded if they had factor loadings of less than 0.5 on all factors or greater than 0.5 on two or more (Tan and Teo, 2000). The factor analysis involved an iterative process, which resulted in the removal of items, until eight distinct factors remained. Table 2 displays the factor analysis results, while Appendix 1 details the refined item measures.

The factor analysis refinement resulted in the elimination of several dimensions of Flow (i.e., Autotelic experience, Challenge, Control, Interactivity, and Immersion). The remaining dimensions of Goal Orientation (GO) and Feedback (FB) overlapped, as with Fang, Zhang and Chan (2013), confirming the dimension of "Goal Orientation and Feedback" (GOFB). An additional item initially assumed to be a measure of Game Quality (GQ4) also loaded on this factor. The item was concerned with interactivity of the game. It was retained as it was deemed to exhibit face validity, given its fit with the notion of Goal Orientation and Feedback. The other remaining dimension of Flow was Concentration (CONC).

Factors of Perceived Usefulness (PU), Game-Task Fit (GTF), Use and Knowledge Improvement (KI) loaded as expected, after a few items not loading appropriately were dropped. For Game Quality (GQ) the first three items (GQ1 to GQ3) loaded together - these items related generally to the ease of use of a game. GQ5 and GQ6 loaded with items of Information Quality. GQ5 referred to personalised information, and GQ6 to attractive features of the game that were appealing, so on face validity they fitted with the other Information Quality (IQ) items that loaded appropriately (IQ1, IQ5 and IQ6).

Table 2: Confirmatory Factor Analysis results

\begin{tabular}{|c|c|c|c|c|c|c|c|c|}
\hline FACTOR & PU & GOFB & $\mathbf{G Q}$ & USE & IQ & CONC & GTF & BEN \\
\hline GO3 & 0.16 & 0.68 & 0.17 & 0.02 & 0.15 & 0.14 & -0.03 & 0.11 \\
\hline FB1 & 0.01 & 0.62 & -0.02 & 0.03 & 0.29 & 0.19 & 0.04 & 0.17 \\
\hline$F B 2$ & 0.11 & 0.77 & 0.16 & -0.04 & 0.10 & 0.10 & 0.06 & 0.03 \\
\hline FB3 & 0.14 & 0.58 & 0.05 & 0.20 & 0.11 & -0.04 & 0.13 & 0.18 \\
\hline GQ4 & 0.14 & 0.64 & 0.26 & 0.06 & 0.02 & 0.06 & 0.32 & 0.06 \\
\hline CONC1 & 0.14 & 0.14 & 0.12 & 0.05 & 0.13 & 0.82 & 0.24 & 0.13 \\
\hline CONC2 & 0.15 & 0.18 & 0.01 & 0.11 & 0.14 & 0.85 & 0.06 & 0.13 \\
\hline PU1 & 0.72 & 0.18 & 0.11 & -0.02 & 0.13 & 0.10 & 0.28 & 0.14 \\
\hline PU2 & 0.84 & 0.20 & 0.05 & 0.04 & 0.08 & 0.14 & 0.11 & 0.07 \\
\hline PU3 & 0.57 & 0.09 & 0.14 & 0.18 & 0.27 & 0.02 & 0.11 & 0.32 \\
\hline PU4 & 0.75 & 0.08 & 0.11 & 0.10 & 0.12 & 0.09 & 0.23 & 0.19 \\
\hline GQ1 & 0.26 & 0.24 & 0.68 & 0.05 & 0.17 & 0.09 & -0.10 & -0.03 \\
\hline GQ2 & 0.09 & 0.26 & 0.73 & 0.03 & 0.07 & -0.03 & 0.20 & -0.02 \\
\hline GQ3 & 0.02 & 0.04 & 0.83 & 0.10 & 0.12 & 0.09 & 0.07 & 0.24 \\
\hline GQ5 & 0.28 & 0.28 & -0.17 & 0.08 & 0.69 & -0.05 & 0.24 & -0.01 \\
\hline GQ6 & 0.14 & 0.19 & 0.11 & 0.10 & 0.65 & 0.09 & 0.19 & 0.14 \\
\hline IQ1 & 0.15 & -0.07 & 0.14 & 0.06 & 0.72 & 0.02 & 0.15 & 0.33 \\
\hline IQ5 & 0.04 & 0.27 & 0.31 & 0.09 & 0.57 & 0.27 & 0.07 & 0.08 \\
\hline IQ4 & 0.06 & 0.30 & 0.25 & -0.11 & 0.61 & 0.25 & 0.15 & 0.01 \\
\hline GTF1 & 0.17 & 0.12 & 0.23 & -0.01 & 0.09 & 0.01 & 0.65 & 0.32 \\
\hline GTF2 & 0.09 & 0.04 & 0.16 & 0.05 & 0.25 & 0.25 & 0.69 & -0.03 \\
\hline GTF3 & 0.39 & -0.02 & 0.27 & -0.18 & 0.17 & 0.23 & 0.57 & 0.15 \\
\hline GTF5 & 0.27 & 0.17 & -0.15 & 0.11 & 0.10 & -0.01 & 0.65 & 0.21 \\
\hline GTF6 & 0.12 & 0.12 & -0.04 & 0.12 & 0.16 & 0.07 & 0.77 & 0.17 \\
\hline USE2 & -0.01 & 0.27 & 0.06 & 0.76 & 0.21 & 0.12 & 0.06 & -0.02 \\
\hline
\end{tabular}




\begin{tabular}{|l|c|c|c|c|c|c|c|c|}
\hline FACTOR & PU & GOFB & GQ & USE & IQ & CONC & GTF & BEN \\
\hline USE3 & 0.15 & -0.07 & 0.09 & 0.88 & -0.04 & 0.03 & 0.08 & 0.02 \\
\hline$K I 1$ & 0.14 & 0.07 & -0.06 & 0.08 & 0.25 & 0.07 & 0.34 & 0.66 \\
\hline$K I 2$ & 0.21 & 0.23 & 0.13 & -0.03 & 0.01 & 0.22 & 0.18 & 0.76 \\
\hline$K I 3$ & 0.25 & 0.24 & 0.14 & -0.05 & 0.22 & 0.07 & 0.14 & 0.67 \\
\hline Expl.Var & $\mathbf{2 . 8 6}$ & $\mathbf{2 . 9 9}$ & $\mathbf{2 . 3 2}$ & $\mathbf{1 . 5 8}$ & $\mathbf{2 . 7 1}$ & $\mathbf{1 . 8 5}$ & $\mathbf{2 . 9 6}$ & $\mathbf{2 . 1 2}$ \\
\hline Prp.TotI & $\mathbf{0 . 1 0}$ & $\mathbf{0 . 1 0}$ & $\mathbf{0 . 0 8}$ & $\mathbf{0 . 0 5}$ & $\mathbf{0 . 0 9}$ & $\mathbf{0 . 0 6}$ & $\mathbf{0 . 1 0}$ & $\mathbf{0 . 0 7}$ \\
\hline
\end{tabular}

\subsubsection{Reliability}

Table 3 displays the number of items of the refined measures, and their reliability. Cronbach Alpha was calculated for each construct. Reliability is indicated if the Cronbach Alpha is greater than 0.6 (Tan and Teo, 2000). All refined measures exhibited reliability.

Table 3: Refined items and Reliability

\begin{tabular}{|l|c|c|c|}
\hline \multicolumn{1}{|c|}{ Construct } & No. of Items (Original) & No. of Items (Refined) & Cronbach Alpha \\
\hline $\begin{array}{l}\text { Flow Dimension 1: } \\
\text { Goal Orientation and Feedback }\end{array}$ & 6 & 4 & 0.78 \\
\hline $\begin{array}{l}\text { Flow Dimension 2: } \\
\text { Concentration }\end{array}$ & 2 & 2 & 0.82 \\
\hline Perceived Usefulness & 4 & 4 & 0.83 \\
\hline Game Quality & 7 & 3 & 0.76 \\
\hline Information Quality & 6 & 5 & 0.80 \\
\hline Game-Task Fit & 6 & 5 & 0.82 \\
\hline Use & 4 & 2 & 0.65 \\
\hline Knowledge Improvement & 5 & 3 & 0.76 \\
\hline
\end{tabular}

\section{Results}

\subsection{Demographic Profile}

Table 4 below summarises the demographic profile of the respondents. The age group of the participants were those between 18 and 25 (49.3\%), and those between 26 and 33 (50.7\%). Since Net generation adults were targeted, there were no respondents under 18 or older than 33 . There was also an almost even split between males $(50.7 \%)$ and females $(49.3 \%)$. In terms of education, the majority were high school graduates (37.3\%) or held undergraduate degrees (44\%). Respondents predominantly came from three regions - South Africa (29.9\%), United Kingdom (30.6\%) and United States (29.9\%) respectively, with a smattering from other regions (9.7\%). The majority of respondents played online games more than once per week $(72.4 \%)$. In terms of the months that had passed since the most recent online game for learning was played there were two major groups - those who were currently playing games for learning (26.9\%), and those who had played more than 5 months ago (41.8\%). In terms of type of game played, the three major categories were Mind/Brain games (44\%), Language games (26.1\%), and Maths/Science games (14.2\%). 
Table 4: Demographic Profile

\begin{tabular}{|c|c|c|}
\hline & Count & Percent \\
\hline \multicolumn{3}{|c|}{ Age } \\
\hline $18-25$ & 66 & 49.3 \\
\hline $26-33$ & 68 & 50.7 \\
\hline \multicolumn{3}{|c|}{ Gender } \\
\hline Male & 68 & 50.7 \\
\hline Female & 66 & 49.3 \\
\hline \multicolumn{3}{|c|}{ Education } \\
\hline Some High School & 6 & 4.5 \\
\hline High School graduate & 50 & 37.3 \\
\hline Undergraduate degree & 59 & 44.0 \\
\hline Postgraduate degree & 19 & 14.2 \\
\hline \multicolumn{3}{|c|}{ Region } \\
\hline South Africa & 40 & 29.9 \\
\hline United Kingdom & 41 & 30.6 \\
\hline United States & 40 & 29.9 \\
\hline Other & 13 & 9.7 \\
\hline \multicolumn{3}{|c|}{ Frequency of play } \\
\hline$<$ once per month & 6 & 4.5 \\
\hline Once per month & 5 & 3.7 \\
\hline 2-3 times per month & 13 & 9.7 \\
\hline Once a week & 13 & 9.7 \\
\hline 2-3 times a week & 44 & 32.8 \\
\hline Daily & 53 & 39.6 \\
\hline \multicolumn{3}{|c|}{ Months since game played } \\
\hline Current & 36 & 26.9 \\
\hline$<1$ & 11 & 8.2 \\
\hline 1 & 10 & 7.5 \\
\hline $1-2$ & 7 & 5.2 \\
\hline $2-3$ & 4 & 3.0 \\
\hline $3-4$ & 2 & 1.5 \\
\hline $4-5$ & 8 & 6.0 \\
\hline$>5$ & 56 & 41.8 \\
\hline \multicolumn{3}{|c|}{ Type of Game } \\
\hline Business & 5 & 3.7 \\
\hline Language & 35 & 26.1 \\
\hline Mind/Brain & 59 & 44.0 \\
\hline Programming & 5 & 3.7 \\
\hline Maths/Science & 19 & 14.2 \\
\hline Typing & 3 & 2.2 \\
\hline Other & 8 & 6.0 \\
\hline
\end{tabular}

\subsection{Descriptive statistics}

Table 5 lists the mean scores and Spearman rank correlations for the refined measures of Game Quality, Information Quality, Flow, Perceived Usefulness, Game-Task Fit, Use and Knowledge Improvement. The measurement scale was from 1 to 5, with 1 being Strongly Agree and 5 being Strongly Disagree. For Flow, the 
mean scores of the two dimensions of Goal Orientation/Feedback, and Concentration were combined. For Use, values are shown from 1 to 7 , where 1 reflects frequent and intense use, and 7, rare use. The correlation of all the constructs was significant at $p<0.05$, save for the correlations between Game Quality and Use, and Use and Knowledge Improvement.

Table 5: Descriptive data for refined constructs

\begin{tabular}{|l|c|c|c|c|c|c|c|c|}
\hline Factor & Mean & FLOW & PU & GQ & IQ & GTF & USE & KI \\
\hline Flow & 1.91 & 1.00 & 0.57 & 0.46 & 0.53 & 0.53 & 0.25 & 0.51 \\
\hline Perceived Usefulness (PU) & 1.90 & & 1.00 & 0.33 & 0.48 & 0.59 & 0.20 & 0.57 \\
\hline Game Quality (GQ) & 1.69 & & & 1.00 & 0.40 & 0.35 & 0.15 & 0.31 \\
\hline Information Quality (IQ) & 2.02 & & & & 1.00 & 0.59 & 0.20 & 0.51 \\
\hline Game-Task Fit (GTF) & 2.04 & & & & & 1.00 & 0.24 & 0.52 \\
\hline Use & 4.10 & & & & & & 1.00 & 0.17 \\
\hline Knowledge Improvement (KI) & 1.88 & & & & & & & 1.00 \\
\hline
\end{tabular}
$p<0.05$

\subsection{Hypothesis Testing}

The 15 hypotheses were tested using Smart PLS to test the path coefficients. Table 6 lists the hypotheses supported, with results also illustrated in Figure 2.9 of the 15 hypotheses were supported. Several hypotheses linked to Use were not supported, e.g. there was no significant effect from Use to Knowledge Improvement, from Game-Task Fit to Use, and Perceived Usefulness to Use. The hypothesised influences of Game Quality on Game-Task Fit and Perceived Usefulness were also not supported, as well as the influence of Information Quality on Perceived Usefulness.

Table 4: Hypotheses Testing

\begin{tabular}{|c|c|c|c|c|c|c|}
\hline Hypothesis & Path from: & To: & $\begin{array}{l}\text { Path } \\
\text { Coeffs. }\end{array}$ & p level & Significance & $\begin{array}{l}\text { Hypotheses } \\
\text { Supported? }\end{array}$ \\
\hline $\mathrm{H} 1$ & USE & $\mathrm{KI}$ & -0.05 & 0.266 & NS & No \\
\hline $\mathrm{H} 2$ & $\mathrm{PU}$ & USE & 0.09 & 0.259 & NS & No \\
\hline $\mathrm{H} 3$ & $\mathrm{PU}$ & $\mathrm{KI}$ & 0.27 & 0.020 & $* *$ & Yes \\
\hline $\mathrm{H} 4$ & GTF & USE & -0.00 & 0.498 & NS & No \\
\hline H5 & GTF & $\mathrm{KI}$ & 0.31 & 0.007 & $* * *$ & Yes \\
\hline $\mathrm{H} 6$ & GTF & PU & 0.39 & 0.000 & $* * *$ & Yes \\
\hline $\mathrm{H} 7$ & FLOW & $\mathrm{KI}$ & 0.25 & 0.052 & * & Yes \\
\hline $\mathrm{H} 8$ & FLOW & USE & 0.26 & 0.009 & $* * *$ & Yes \\
\hline $\mathrm{H} 9$ & FLOW & PU & 0.18 & 0.061 & * & Yes \\
\hline $\mathrm{H} 10$ & $\mathrm{GQ}$ & PU & 0.10 & 0.101 & NS & No \\
\hline $\mathrm{H} 11$ & $\mathrm{GQ}$ & GTF & 0.12 & 0.106 & NS & No \\
\hline $\mathrm{H} 12$ & $\mathrm{GQ}$ & FLOW & 0.23 & 0.002 & $* * *$ & Yes \\
\hline $\mathrm{H} 13$ & $\mathrm{IQ}$ & PU & 0.14 & 0.100 & NS & No \\
\hline $\mathrm{H} 14$ & IQ & GTF & 0.47 & 0.000 & $* * *$ & Yes \\
\hline $\mathrm{H} 15$ & $\mathrm{IQ}$ & FLOW & 0.48 & 0.000 & $* * *$ & Yes \\
\hline
\end{tabular}

The adjusted R-squared value for Knowledge Improvement was 42.5\%, meaning that Game-Task Fit, Perceived Usefulness and Flow respectively accounted for a substantial portion of the variance in Knowledge Improvement, but Use did not play a significant role. Perceived Usefulness was explained primarily by GameTask Fit and Flow, while Game-Task Fit was mainly influenced by Information Quality. Both Information Quality and Game Quality influenced Flow. 


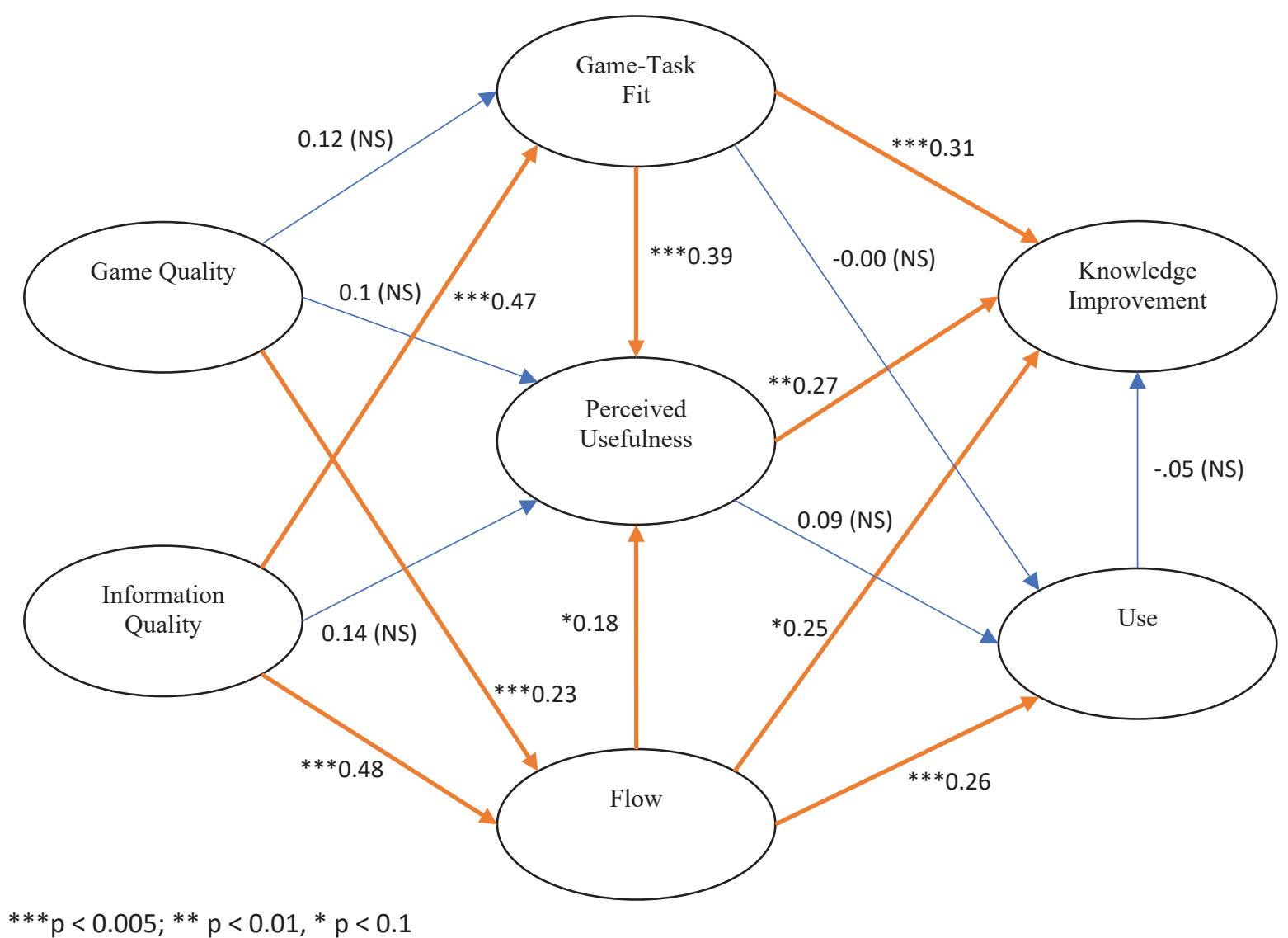

Figure 2: Tested Model

\section{Discussion and Implications}

The results suggest that the intensity and frequency of game usage do not play a prominent role in online gamebased learning effectiveness, in the light of other variable such as Game-Task Fit, Perceived Usefulness and Flow. This is counter to much theory, whereby in task-technology fit theory, better fit and utilisation jointly lead to improved performance (Goodhue and Thompson, 1995). Similarly in the IS success model, Usage is deemed to lead to the accrual of benefits (DeLone and Mclean, 2003). That this Usage to Performance/Benefits relationship does not hold in this study suggests that a learner who uses online game-based learning fairly infrequently, and not too intensely may gain just as much knowledge from the game use as one who is an intense and frequent game player. A possibility exists that there are moderating variables such as the prior knowledge of a user, learning style, individual cognition, experience with technology or even type of game and type of knowledge being taught that might affect the strength of relationship between frequency and intensity of Usage and Knowledge Improvement. Alternatively, there may exist a non-linear relationship between Usage and Knowledge Improvement, whereby up to a certain threshold of Use, there is a positive impact on Knowledge Improvement, but thereafter further increases in intensity and frequency of Usage yield no further improvements in knowledge gained. This threshold may vary with the type of game and complexity of knowledge being taught.

It was found too that Game-Task Fit and Perceived Usefulness do not contribute to greater levels of Usage for online game-based learning amongst the sample, contrary to task-technology fit and technology acceptance studies on e-learning (Chen, 2010, Lin, 2012). On the other hand, Flow is found to have a positive influence on Usage, suggesting that the experience of flow is the main driver of the intensity and frequency of Usage when it comes to online game-based learning. Hence the hedonic motivation for game use, may be stronger than the utilitarian (Lin, Wang and Chou, 2012). Games may be considered as dual-purpose IS. It has been found that dual-purpose IS usage tends to be driven more by hedonic motivators (Wu and Lu, 2013). Our findings confirm this. Furthermore, in the sample, most games were in the category of mind/brain games or language games, where the fun element of game-play may have overridden the learning task in motivating frequent and intense use. There may also be a non-linear relationship whereby below a certain threshold, Usage is driven by both 
utilitarian factors (Game-Task Fit and Perceived Usefulness) and Flow, but beyond that increased levels of usage are driven by the flow experience.

Another reason for the lack of influence of Usage may be that Usage may have been inappropriately conceptualised for the context (Burton-Jones and Straub 2006) - in this study the context being online gamebased learning. Burton-Jones and Straub (2006) suggest that a richer measure of IS Usage could be cognitive absorption, which is the extent to which a user becomes absorbed in usage activity (Agarwal and Karahanna, 2000). This is akin to the Flow experience found to be important for game-play (Fang, Zhang and Chan, 2013). Hence Flow may be a more appropriate measure of Usage than measures such as frequency and intensity of use.

As hypothesised the knowledge gained from online game-based learning was influenced by Game-Task Fit, Perceived Usefulness and Flow in that order, but not by Usage. While Perceived Usefulness was not originally included in the Delone and Mclean IS success models (1992, 2003), it has been motivated for inclusion in various adaptations of the model, on the basis that Perceived Usefulness is a more suitable characteristic of IS success than IS Usage when conceptualised as a behavioural variable (Seddon, 1997). Our study provides support for the inclusion of Perceived Usefulness as an important characteristic in online game-based learning, in fact more important than frequency and intensity of game Use for learning effectiveness.

Game Quality, akin to System Quality in IS success (Delone and McLean, 2003), and Information Quality were hypothesised as antecedents of Game-Task Fit, Perceived Usefulness and Flow respectively. Game Quality was significantly related to Flow only. Game quality was operationalised as the availability, ease of use and userfriendliness of the game. It is telling that these characteristics drove the more hedonic motivation of Flow and subsequently Usage, and not the utilitarian concepts of Perceived Usefulness and Game-Task Fit, which were the main influencers of Knowledge Improvement. Information or content in a learning context is an important element for knowledge acquisition. Hence as expected Information Quality had a significant influence on GameTask Fit and Flow, but surprisingly not Perceived Usefulness. The influence of Information Quality on Perceived Usefulness may then be indirect via Game-Task Fit.

\section{Conclusion}

By employing a multi-theoretic approach, this study has provided a more comprehensive view on factors leading to learning effectiveness than those studies based on a single theoretical perspective. Game-Task Fit, Perceived Usefulness and Flow were all shown to be important for Knowledge Improvement through online game-based learning. Game Quality enhanced Flow, while Information Quality influenced both Game-Task Fit and Flow.

The results suggest that more frequent and intense Usage of games does not necessarily lead to Knowledge Improvement, as such usage is motivated primarily by the flow experience, where the fun of game-play rather than learning is the prime driver. Flow does contribute to Knowledge Improvement but not necessarily by more frequent and intense Usage of games. The primary drivers of Knowledge Improvement through online gamebased learning usage are Game-Task Fit and Perceived Usefulness.

The findings need to be interpreted in the light of the type of game respondents considered in answering. The vast majority answered with respect to mind-brain games and language games. Few referred to games used for formal learning of subjects such as computer programming, business strategy, etc. Future research might focus on the use of online games in formal learning settings, such as in university degree programmes.

Future research could also consider how to improve operationalisation of constructs such as Flow and Game Usage. Hoffman and Novak (2009) note that Flow can be measured using either a uni-dimensional or multidimensional construct. The latter was chosen in this study, but of the seven initial dimensions expected only two were validated, suggesting that perhaps a uni-dimensional measure would have been more appropriate. The lack of influence of more frequent and intense game Usage on Knowledge Improvement suggests the perhaps richer conceptualisations of Usage are required when considering online game-based learning. Other lines of enquiry could include investigating the moderating factors that intervene between game usage and knowledge improvement. To interrogate the potentially non-linear relationships between variables, techniques such as regression splines could be employed. 


\section{References}

Agarwal, R. and Karahanna, E., 2000. Time flies when you're having fun: Cognitive absorption and beliefs about information technology usage. MIS Quarterly, 24(4), pp.665-694.

All, A., Plovie, B., Castellar, E. P. N., and Van Looy, J., 2017. Pre-test influences on the effectiveness of digital-game based learning: A case study of a fire safety game. Computers \& Education, 114, pp.24-37.

Annetta, L.A., 2010. The "I's" have it: A framework for serious educational game design. Review of General Psychology, 14(2), pp.105-113.

Barlett, J.E., Kotrlik, J.W. and Higgins, C.C., 2001. Organizational research: Determining appropriate sample size in survey research. Information Technology, Learning, and Performance Journal, 19(1), pp.43-50.

Bekebrede, G., Warmelink, H.J.G. and Mayer, I.S., 2011. Reviewing the need for gaming in education to accommodate the Net generation. Computers and Education, 57(2), pp.1521-1529.

Bellotti, F., Kapralos, B., Lee, K., Moreno-Ger, P. and Berta, R., 2013. Assessment in and of serious games: An overview. Advances in Human-Computer Interaction, Article ID 136864, pp.1-11.

Besharat, A., Kumar, A., Lax, J.R. and Rydzik, E.J., 2013. Leveraging virtual attribute experience in video games to improve brand recall and learning. Journal of Advertising, 42(2), pp.170-182.

Brom, C., Šisler, V. and Slavík, R., 2010. Implementing digital game-based learning in schools: Augmented learning environment of 'Europe 2045'. Multimedia Systems, 16(1), pp.23-41.

Brom, C., Preuss, M. and Klement, D., 2011. Are educational computer micro-games engaging and effective for knowledge acquisition at high-schools? A quasi-experimental study. Computers and Education, 57(3), pp.1971-1988.

Burton-Jones, A. and Straub Jr, D.W., 2006. Reconceptualizing system usage: An approach and empirical test. Information Systems Research, 17(3), pp.228-246.

Butler, A.C., Godbole, N. and Marsh, E.J., 2013. Explanation feedback is better than correct answer feedback for promoting transfer of learning. Journal of Educational Psychology, 105(2), pp.290-298.

Calleja, G., 2007. Digital game involvement: A conceptual model. Games and Culture: A Journal of Interactive Media, 2(3), pp.236-260.

Cane, S. and McCarthy, R., 2009. Analyzing the factors that affect information systems use: A task-technology fit metaanalysis. Journal of Computer Information Systems, 50(1), pp.108-123.

Cardella, E., Ewing, B.T. and Williams, R.B., 2016. Price volatility and residential electricity decisions: Experimental evidence on the convergence of energy generating source. Energy Economics. 62, pp.428-437.

Cerasoli, C.P. and Ford, M.T., 2014. Intrinsic motivation, performance, and the mediating role of mastery goal orientation: A test of self-determination theory. Journal of Psychology, 148(3), pp.267-286.

Chang, C. C., Warden, C. A., Liang, C., and Lin, G. Y., 2018. Effects of digital game-based learning on achievement, flow and overall cognitive load. Australasian Journal of Educational Technology, 34(4), pp.155-167.

Chang, Y.C., Peng, H.Y. and Chao, H.C., 2010. Examining the effects of learning motivation and of course design in an instructional simulation game. Interactive Learning Environments, 18(4), pp.319-339.

Charoenying, T., 2010. Accountable game design: Structuring the dynamics of student learning interactions. Journal of Educational Computing Research, 43(2), pp.135-163.

Chen, H.J., 2010. Linking employees' e-learning system use to their overall job outcomes: An empirical study based on the IS success model. Computers and Education, 55(4), pp.1628-1639.

Chen, Z., Liao, C.C.Y., Cheng, H.N.H., Yeh, C.Y.C. and Chan, T., 2012. Influence of game quests on pupils' enjoyment and goal-pursuing in math learning. Educational Technology and Society, 15(2), pp.317-327.

Cheng, M., She, H. and Annetta, L.A., 2015. Game immersion experience: Its hierarchical structure and impact on gamebased science learning. Journal of Computer Assisted Learning, 31(3), pp.232-253.

Chin, J., Dukes, R. and Gamson, W., 2009. Assessment in simulation and gaming: A review of the last 40 years. Simulation and Gaming, 40(4), pp.553-568.

Chiu, Y., Kao, C. and Reynolds, B.L., 2012. The relative effectiveness of digital game-based learning types in English as a foreign language setting: A meta-analysis. British Journal of Educational Technology, 43(4), pp.E104-E107.

Cohard, P., 2019. Evaluation of serious game user experience: the role of emotions. Electronic Journal of Information Systems Evaluation, 22(2), pp.128-141.

Connolly, T.M., Boyle, E.A., MacArthur, E., Hainey, T. and Boyle, J.M., 2012. A systematic literature review of empirical evidence on computer games and serious games. Computers and Education, 59(2), pp.661-686.

Cornillie, F., Clarebout, G. and Desmet, P., 2012. Between learning and playing? Exploring learners' perceptions of corrective feedback in an immersive game for English Pragmatics. Recall, 24(3), pp.257-278.

Dalgarno, B. and Lee, M.J., 2010. What are the learning affordances of 3-D virtual environments? British Journal of Educational Technology, 41(1), pp.10-32.

De Freitas, S. and Oliver, M., 2006. How can exploratory learning with games and simulations within the curriculum be most effectively evaluated? Computers and Education, 46(3), pp.249-264.

Del Blanco, Á., Torrente, J., Marchiori, E.J., Martínez-Ortiz, I., Moreno-Ger, P. and Fernández-Manjón, B., 2012. A framework for simplifying educator tasks related to the integration of games in the learning flow. Journal of Educational Technology and Society, 15(4), pp.305-318.

DeLone, W.H. and McLean, E.R., 1992. Information systems success: The quest for the dependent variable. Information Systems Research, 3(1), pp.60-95. 
DeLone, W.H. and McLean, E.R., 2003. The DeLone and McLean model of information systems success: A ten-year update. Journal of Management Information Systems, 19(4), pp.9-30.

Domagk, S., Schwartz, R.N. and Plass, J.L., 2010. Interactivity in multimedia learning: An integrated model. Computers in Human Behavior, 26(5), pp.1024-1033.

Erhel, S. and Jamet, E., 2013. Digital game-based learning: Impact of instructions and feedback on motivation and learning effectiveness. Computers and Education, 67, pp.156-167.

Evans, R.R. and Forbes, L., 2012. Mentoring the 'Net generation': Faculty perspectives in health education. College Student Journal, 46(2), pp.397-404.

Feng, L., 2011. Avoiding internet addiction when integrating digital games into teaching. Social Behavior and Personality: An International Journal, 39(10), pp.1325-1336.

Fang, X., Zhang, J. and Chan, S.S., 2013. Development of an instrument for studying flow in computer game play. International Journal of Human-Computer Interaction, 29(7), pp.456-470.

Fu, F., Su, R. and Yu, S., 2009. EGameFlow: A scale to measure learners' enjoyment of elearning games. Computers and Education, 52(1), pp.101-112.

Girard, C., Ecalle, J. and Magnan, A., 2013. Serious games as new educational tools: How effective are they? A metaanalysis of recent studies. Journal of Computer Assisted Learning, 29(3), pp.207-219.

Goodhue, D.L. and Thompson, R.L., 1995. Task-technology fit and individual performance. MIS Quarterly, 19(2), pp.213236.

Grover, V. and Lyytinen, K., 2015. New state of play in Information Systems research: The push to the edges. MIS Quarterly, 39(2), pp.271-296.

Gu, X., Zhu, Y. and Guo, X., 2013. Meeting the "digital natives": Understanding the acceptance of technology in classrooms. Educational Technology and Society, 16(1), pp.392-402.

Guillén-Nieto, V. and Aleson-Carbonell, M., 2012. Serious games and learning effectiveness: The case of It's a deal! Computers and Education, 58(1), pp.435-448.

Hamam, A. and Saddik, A.E., 2013. Toward a mathematical model for quality of experience evaluation of Haptic applications. IEEE Transactions on Instrumentation and Measurement, 62(12), pp.3315-3322.

Hess, T. and Gunter, G., 2013. Serious game-based and nongame-based online courses: Learning experiences and outcomes. British Journal of Educational Technology, 44(3), pp.372-385.

Hoffman, D.L. and Novak, T.P., 2009. Flow online: Lessons learned and future prospects. Journal of Interactive Marketing, 23(1), pp.23-34.

Hsu, C. and Lu, H., 2004. Why do people play on-line games? An extended TAM with social influences and flow experience. Information and Management, 41(7), pp.853-868.

Hughes, D., 2010. Steps to leadership action learning sets: "make it challenging but not too challenging". Action Learning: Research and Practice, 7(1), pp.75-81.

Hong, J., Hwang, M., Lu, C., Cheng, C., Lee, Y. and Lin, C., 2009. Playfulness-based design in educational games: A perspective on an evolutionary contest game. Interactive Learning Environments, 17(1), pp. 15-35.

Janczyk, M. and Grabowski, J., 2011. The focus of attention in working memory: Evidence from a word updating task. Memory,19(2), pp.211-225.

Jong, B., Lai, C., Hsia, Y., Lin, T. and Lu, C., 2013. Using game-based cooperative learning to improve learning motivation: A study of online game use in an operating systems course. IEEE Transactions on Education, 56(2), pp.183-190.

Jovanovic, M., Starcevic, D., Minovic, M. and Stavljanin, V., 2011. Motivation and multimodal interaction in model-driven educational game design. IEEE Transactions on Systems, Man and Cybernetics: Part A, 41(4), pp.817-824.

Jung, T. K. and Won-Hyung Lee., 2013. Dynamical model and simulations for gamification of learning. International Journal of Multimedia and Ubiquitous Engineering, 8(4), pp.179-189.

Khanlarian, C.J. and Singh, R., 2014. An exploratory study of the online learning environment. Issues in Accounting Education, 29(1), pp.117-147.

Khayun, V., Ractham, P. and Firpo, D., 2012. Assessing e-excise success with DeLone and McLean's model. Journal of Computer Information Systems, 52(3), pp.31-40.

Khojah, M., 2019. Studying the impact of a serious game on students learning using Task-Technology Fit Model. In Proceedings of the $25^{\text {th }}$ Americas Conference on Information Systems (AMCIS 2019), Cancun: AIS.

Kiili, K., 2005. Digital game-based learning: Towards an experiential gaming model. The Internet and Higher Education, 8(1), pp.13-24.

Kuss, D.J., Louws, J. and Wiers, R.W., 2012. Online gaming addiction? motives predict addictive play behavior in massively multiplayer online role-playing games. CyberPsychology, Behavior and Social Networking, 15(9), pp.480-485.

Lee, D.Y. and Lehto, M.R., 2013. User acceptance of YouTube for procedural learning: An extension of the technology acceptance model. Computers and Education, 61, pp.193-208.

Lee, J., Cerreto, F.A. and Lee, J., 2010. Theory of planned behavior and teachers' decisions regarding use of educational technology. Educational Technology and Society, 13(1), pp.152-164.

Lin, C. H., Huang, S. H., Shih, J. L., Covaci, A. and Ghinea, G., 2017. Game-based learning effectiveness and motivation study between competitive and cooperative modes. In 2017 IEEE 17th International Conference on Advanced Learning Technologies (ICALT), pp.123-127. IEEE.

Li, M., Jiang, Q., Tan, C. and Wei, K., 2014. Enhancing user-game engagement through software gaming elements. Journal of Management Information Systems, 30(4), pp.115-150. 
Lin, W., 2012. Perceived fit and satisfaction on web learning performance: IS continuance intention and task-technology fit perspectives. International Journal of Human-Computer Studies, 70(7), pp.498-507.

Lin, H., Wang, Y. and Chou, C., 2012. Hedonic and utilitarian motivations for physical game systems use behavior. International Journal of Human-Computer Interaction, 28(7), pp.445-455.

Lowry, P.B., D'Arcy, J., Hammer, B. and Moody, G.D., 2016. "Cargo Cult" science in traditional organization and information systems survey research: A case for using non-traditional methods of data collection, including Mechanical Turk and online panels. Journal of Strategic Information Systems, 25(3), pp.232-240.

Ma, C., Chao, C. and Cheng, B., 2013. Integrating technology acceptance model and task technology fit into blended Elearning system. Journal of Applied Sciences, 13(5), pp.736-742.

McGill, T., Klobas, J. and Renzi, S., 2011. LMS use and instructor performance: The role of task-technology fit. International Journal on E-Learning, 10(1), pp.43-62.

Moos, D. C. and Marroquin, E., 2010. Multimedia, hypermedia, and hypertext: Motivation considered and reconsidered. Computers in Human Behavior, 26(3), pp.265-276.

Morris, H., 2011. The Net generation, the knowledge economy and on-line learning: Who is learning online and how? Contemporary Social Science, 6(2), pp.237-254.

Mwangi, R.W. Waweru, R. and Mwathi, C.W., 2011. Integrating ICT with education: Designing an educational computer game for teaching functions in undergraduate mathematics. Journal of Theoretical and Applied Information Technology, 26(1), pp.53-58.

Nicholson, S., 2011. Making gameplay matter: Designing modern educational tabletop games. Knowledge Quest, 40(1), pp.60-65.

Pace, S., 2004. A grounded theory of the flow experiences of web users. International Journal of Human-Computer Studies, 60(3), pp.327-363.

Peng, W., 2009. Design and evaluation of a computer game to promote a healthy diet for young adults. Health Communication, 24(2), pp.115-127.

Pennington, R.R. and Kelton, A.S., 2016. How much is enough? An investigation of nonprofessional investors' information search and stopping rule use. International Journal of Accounting Information Systems, 21, pp.47-62.

Perttula, A., Kiili, K., Lindstedt, A. and Tuomi, P., 2017. Flow experience in game based learning-a systematic literature review. International Journal of Serious Games, 4(1), pp.57-72.

Poels, K., de Kort, Y. and IJsselsteijn, W., 2012. Identification and categorization of digital game experiences: A qualitative study integrating theoretical insights and player perspectives. Westminster Papers in Communication and Culture, 9(1), pp.107-129.

Robles-Flores, J. and Roussinov, D., 2012. Examining question-answering technology from the task technology fit perspective. Communications of the Association for Information Systems, 30, 439-454.

Rosen, L.D., 2011. Teaching the iGeneration. Educational Leadership, 68(5), pp.10-15.

Saeed, K.A., and Abdinnour-Helm, S., 2008. Examining the effects of information system characteristics and perceived usefulness on post adoption usage of information systems. Information and Management, 45(6), pp.376-386.

Seddon, P.B., 1997. A respecification and extension of the DeLone and McLean model of IS success. Information Systems Research, 8(3), pp.240-253.

Setia, P., Venkatesh, V., and Joglekar, S., 2013. Leveraging digital technologies: How information quality leads to localized capabilities and customer service performance. MIS Quarterly, 37(2), pp.565-A4.

Shafer, D.M., Carbonara, C.P. and Popova, L., 2011. Spatial presence and perceived reality as predictors of motion-based video game enjoyment. Presence: Teleoperators and Virtual Environments, 20(6), pp.591-619.

Skiba, D.J. and Barton, A.J., 2006. Adapting your teaching to accommodate the Net generation of learners. Online Journal of Issues in Nursing, 11(2), pp.15-15.

So, H., Choi, H., Lim, W.Y. and Xiong, Y., 2012. Little experience with ICT: Are they really the Net generation studentteachers? Computers and Education, 59(4), pp.1234-1245.

Tan, M. and Teo, T., 2000. Factors influencing the adoption of Internet banking, Journal for the Association of Information Systems, 1(5), pp.1-42.

Teo, T.S., Lim, V.K. and Lai, R.Y., 1999. Intrinsic and extrinsic motivation in internet usage. Omega, 27(1), pp.25-37.

Thong, J. Y., Hong, S. and Tam, K.Y., 2006. The effects of post-adoption beliefs on the expectation-confirmation model for information technology continuance. International Journal of Human-Computer Studies, 64(9), pp.799-810.

Valtonen, T., Dillon, P., Hacklin, S. and Väisänen, P., 2010. Net generation at social software: Challenging assumptions, clarifying relationships and raising implications for learning. International Journal of Educational Research, 49(6), pp.210-219.

Valtonen, T., Pontinen, S., Kukkonen, J., Dillon, P., Vaisanen, P. and Hacklin, S., 2011. Confronting the technological pedagogical knowledge of Finnish Net generation student teachers. Technology, Pedagogy and Education, 20(1), pp.3-18.

Vanduhe, V. Z., Nat, M., and Hasan, H. F., 2020. Continuance intentions to use gamification for training in higher education: Integrating the Technology Acceptance Model (TAM), Social Motivation, and Task Technology Fit (TTF). IEEE Access, 8, pp.21473-21484.

Vogel, J.J., Vogel, D.S., Cannon-Bowers, J., Bowers, C.A., Muse, K. and Wright, M., 2006. Computer gaming and interactive simulations for learning: A meta-analysis. Journal of Educational Computing Research, 34(3), pp.229-243.

Walter, P., 2013. Greening the Net generation: Outdoor adult learning in the digital age. Adult Learning, 24(4), pp.151-158. 
Wang, Y., Wang, H. and Shee, D.Y., 2007. Measuring e-learning systems success in an organizational context: Scale development and validation. Computers in Human Behavior, 23(4), pp.1792-1808.

Whitton, N., 2011. Game engagement theory and adult learning. Simulation and Gaming, 42(5), pp.596-609.

Wu, J. and Lu, X., 2013. Effects of extrinsic and intrinsic motivators on using utilitarian, hedonic, and dual-purposed information systems: A meta-analysis. Journal of the Association for Information Systems, 14(3), pp.153-191.

Wu, W., Hsiao, H., Wu, P., Lin, C. and Huang, S., 2012. Investigating the learning-theory foundations of game-based learning: A meta-analysis. Journal of Computer Assisted Learning, 28(3), pp.265-279.

\section{Appendix 1: Refined Item Measures used (See Table 1 for Sources)}

(Answered with respect to the most recent online game-based learning experience)

\section{Flow - Orientation and Feedback}

GO3. Because of the online game instructions, my goals were clearly defined.

FB1. While playing this online game, I had a good idea about how well I was doing.

FB2. I was aware of how well I was performing in this online game.

FB3. I received immediate feedback on my actions.

GQ4. The online game provided interactive features between myself and the system.

Flow - Concentration

CONC1. My attention was focused entirely on the online game that I was playing.

CONC2. When playing this online game, I totally concentrated on what I was doing.

Perceived Usefulness

PU1. Learning with the online game improved my ability to perform the task.

PU2. Learning with the online game improved my outcome in regards to performing the task.

PU3. Learning with the online game increased my understanding of how to perform the task.

PU4. Using the online game made it easier to learn how to perform the task.

\section{Game Quality}

GQ1. The online game is available when I need to play it.

GQ2. The online game was easy to use.

GQ3. The online game was user-friendly.

Information Quality

GQ5. The online game provided personalized information.

GQ6. The online game had attractive features that were appealing.

IQ1. The online game provided information that was needed.

IQ4. The online game provided sufficient information.

IQ5. The online game provided information that was easy to understand.

\section{Game-Task Fit}

GTF1. Using this online game fits well with the way I like to improve my learning.

GTF2. Using this online game fits well with the way I like to study.

GTF3. This online game provided good functionality to help me complete my learning task.

GTF5. By utilizing the online game I could concentrate more on my other studies.

GTF6. I learned better with this online game than without it.

Use

USE2. On average, I used the online game [Rarely to a few times a day]

USE3. On an average working day, I used the online game [Rarely to more than 4 hours]

\section{Knowledge Improvement}

KI1. The online game increased my knowledge.

$\mathrm{K}$ I2. I caught the basic ideas of the knowledge taught.

KI3. I tried to apply the knowledge in the online game. 